\title{
Mental and Cardiovascular Health of Portuguese Subjects in a Situation of Economic Insufficiency
}

\author{
Eduardo Gonçalves' ${ }^{1}$, Emanuel Marco Moniz ${ }^{1}$, Saul Neves de Jesus ${ }^{2}$ \\ ${ }^{1}$ Department of Psychiatry and Mental Health of Hospital Center of Algarve, Faro, Portugal \\ ${ }^{2}$ Department of Psychology of Faculty of Social and Human Sciences of University of Algarve, Faro, Portugal \\ Email: eduar.goncalves@gmail.com
}

Received 30 August 2015; accepted 16 October 2015; published 19 October 2015

Copyright (C) 2015 by authors and Scientific Research Publishing Inc.

This work is licensed under the Creative Commons Attribution International License (CC BY). http://creativecommons.org/licenses/by/4.0/

c) (7) Open Access

\begin{abstract}
Economic insufficiency causes stress and negative affects. Poverty is self-perpetuated, also due to a particular pattern of economic behaviors induced by negative affects and stress. Often, loneliness occurs together with economic insufficiency. For this study, it has been selected a sample of convenience. A positive correlation between anxiety/depression and negative affects is presented. Dispositional optimism and social support, factors which contribute to health, serve as buffers, in negative correlation, of the negative impact of negative affects, due to financial restraint, on health. Financial management is negatively correlated with the lack of cardiovascular health, and cardiovascular dysfunction correlates positively with loneliness, in this study. Positive affects correlate positively with resilience skills, which correlate negatively with depression. Within this context, psychobiological therapeutic interventions and psychotherapy, which also target psychological dysfunction related to economic behavior of persons in a situation of poverty, would be beneficial.
\end{abstract}

\section{Keywords}

Poverty, Stress, Affects, Depression, Heart Rate Variability, Social Support, Resilience, Economic Behavior

\section{Introduction (Theoretical Framework)}

\subsection{Stress and Negative Affects Caused by Economic Insufficiency (Poverty)}

Poverty causes lack of opportunities, reduced accessibility to resources and is associated with a greater likelih-

How to cite this paper: Gonçalves, E., Moniz, E.M. and de Jesus, S.N. (2015) Mental and Cardiovascular Health of Portuguese Subjects in a Situation of Economic Insufficiency. Open Journal of Psychiatry, 5, 374-385. 
ood of life events with traumatic potential. By acting through stressors agents of socio-economic nature, such as unemployment and the difficulty of access to housing, it is much more likely that poverty precedes mental disorders, such as anxiety and depression, and it is an important risk factor for mental illness [1]. The relationship between poverty and mental illness is bidirectional, that is, poverty is a risk factor for certain mental illnesses, which, in turn, worsen the economic condition of the patient and their families. Some factors, such as education and employment, have a two-way relationship with poverty. The lack of employment results in financial difficulties, and poverty results in reduced opportunity to obtain gainful employment. Unemployed persons and those who fail to obtain employment have more depressive symptoms than individuals who can get a job [2]. Limited resources, resulting in reduced opportunity for education, which prevent access to most skilled jobs, increase individual vulnerability and insecurity contributing to a persistently low social capital. The prevalence of common mental disorders is higher among individuals with low levels of education. Chronic poverty is often associated with low levels of family and community support, alcoholism, insecurity and violent crime, family abuse and family desertion, particularly by men [1]. In a review of 115 studies, 79\% showed a negative association between indicators of poverty and mental health [3]. Several studies have shown: high levels of cortisol in subjects with lower financial incomes and less education [4] [5]; lower economic status measured by occupational status [6] [7]. Measures, consisting generically in increased personal financial income, determine: reduction in hospitalization for mental health problems [8]; lower consumption of anxiolytics [9]; increased mental health [10]-[12]. Poverty causes negative affects and stress, and these effects alter the economic behavior of persons concerning time preference (i.e., the degree of preference for present consumption over future consumption) and assumption of risky economic behavior, limiting economic decision-making, and thus favoring habitual behaviors, not oriented for objectives, perpetuating poverty itself [13]. Decision making requires individuals, in difficult circumstances of business transaction, i.e., with less budget (and resulting lower capacity to acquire larger amount of desirable goods), to recruit scarce cognitive resources, which subsequently will be reflected in worse performances in tasks that require integrity of executive function, such as Stroop [14] [15]. Thus, cognitive deficit of executive function that characterizes economic insufficiency does not ensure the ability to defer rewards, implied in economic behavior related to time preference. There are three ways to break the cycle of economic insufficiency/poverty and improve well-being: the implementation of policy measures for direct poverty reduction; the management of the psychological consequences of economic insufficiency; the change in economic behavior arising from these [16]. Since the deteriorating effects of stress and negative affects in economic behavior can occur even in individuals who do not suffer from depression, therapeutic interventions of psychobiological nature and psychotherapy bring economic benefits even in non-clinical populations [17].

\subsection{Stress, Positive and Negative Affects, Tripartite Model of Anxiety and Depression and Brain Electrophysiological Activity}

Positive affectivity is a characteristic that describes how animals and humans experience positive emotions and interact with each other and their environments. Persons with increased positive affectivity are enthusiastic, energetic, confident, active and alert. Persons with low levels of positive affectivity are characterized by sadness, apathy, anxiety, stress and not rewarding social involvement. Happiness, high levels of well-being and self-esteem are often associated with increased levels of positive affectivity [18]. Positive affectivity provides a rupture of stress and supports ongoing efforts to replenish depleted resources from stress [19]. Positive affectivity and negative affectivity are not independent. Negative affectivity is a general dimension of subjective distress, due to stress and not satisfying social involvement, and encompasses a variety of aversive mood states, including anger, contempt, disgust, guilt, fear and nervousness. Low negative affectivity levels are characterized by a state of calm and serenity. Watson and Clark (1984) have defined negative affectivity as a dimension of dispositional mood that reflects individual differences relating to negative emotions and self-concept. These authors concluded that individuals who express high levels of negative affectivity envisage themselves and their involvement in generally negative terms [20]. Individuals with high negative affectivity levels have higher levels of stress, anxiety and dissatisfaction with life, and tend to focus on unpleasant aspects of themselves, the world, the future and others [21]. The tripartite model of anxiety and depression, developed by Clark and Watson (1991), proposes that anxiety and depressive disorders overlap considerably by a general, not specific, factor, negative affectivity, which reflects the level of aversive feelings present in an individual. The two remaining factors of this model are positive affectivity, which, when low, is relatively specific for depression, and physiological ac- 
tivation, which is relatively specific to anxiety [22]. Several authors consider anxiety and depression a single disorder's entity. Lovibond and Lovibond (1995), authors of anxiety, depression and stress scales (DASS), assume that psychological disorders are not categories, that is, the differences between depression, anxiety and stress, experienced by normal subjects and patients, are essentially level ones: depression is characterized mainly by the loss of self-esteem and motivation, and is associated with the perception of low probability of achieving life goals that are meaningful to the individual as a person; anxiety emphasizes the links between persistent state of anxiety and intense fear responses; stress suggests states of excitement and persistent tension, with low resistance to frustration and disappointment. According to this model, depression is defined by dysphoria, hopelessness, devaluation, self-depreciation, lack of interest, anhedonia and inertia, anxiety is defined by autonomic arousal, skeletal muscle effects, situational anxiety and subjective experience of anxious affect, and stress is defined by difficulty in relaxing, nervous excitation, easy agitation, irritability/excessive reactivity and impatience [23]. The components of the tripartite model of anxiety and depression have been linked to neurophysiological measures of anxiety and depression. Increased in left frontal electrophysiological activity is associated with an increased positive affectivity, i.e., the decrease of depressive states, while decreased left frontal electrophysiological activity is associated with decreased positive affectivity, i.e. the increase of depressive states. Anxiety disorders have repeatedly been associated with an increase in right prefrontal cortex and amygdala activity, abnormalities similar to those reported in depressed subjects [24]-[28]. Neuro-stimulation, in particular, high frequency (above $1 \mathrm{~Hz}$ ) repetitive transcranial magnetic stimulation (rTMS) over the left dorso-lateral prefrontal cortex treats depressive states [29].

\subsection{Loneliness}

Loneliness is an unpleasant experience that occurs when personal network of social relationships is significantly deficient in quantity and/or quality. Predisposing factors that may increase personal risk for loneliness include individual differences in personality and behavior, such extreme shyness or lack of social skills. Within a society, social norms can also affect the tendency to feel lonely. The onset of loneliness is often initiated by a previous event, usually a change or loss in/of an emotional relationship, through death or divorce, or a disruption of social relationship created by the move to a new school, city or employment. The intensity of loneliness may increase if the individual evaluates his/her own situation as worse than that of their peers, or attributes the causes of their loneliness to personal inadequacies. Individuals with a solitary trait, compared to persons in a solitary state, are more likely to have poor social skills, attribute their loneliness to undesirable factors and have difficulty to overcoming their social deficits. Classically, it is distinguished emotional loneliness from social loneliness, wherein the first encompasses the lack of emotional ties inherent to intimate relationships, while bereavement, divorce or emptiness feelings within marriage are the likely background of this latter kind of loneliness. Loss of employment, exclusion from the peer group and not belonging to community organizations are the likely history of social loneliness. Several studies have shown that loneliness is more prevalent among lower financial income groups [30].

\subsection{Dispositional Optimism}

Well-being is the result of a cognitive and emotional subjective evaluation, and its level is determined by the individual's life satisfaction, satisfaction with leisure and professional practices, satisfaction with others and everyday experiences of positive emotions. Based on the behavioral theory of self-regulation, Scheier and Carver (1994) elaborated life orientation test (LOT), in order to measure dispositional optimism, as a personal construct [31]. Segerstrom and Nes (2006) found better psychological health indices associated with dispositional optimism [32]. Chang (1998) found that dispositional optimism is a significant moderator of the relationship between stress and psychological well-being [33]. Vickers and Vogeltanz (2000) found that the lack of optimism is a predictor of depression [34].

\subsection{Social Support}

Rodin and Salovey, cited by Pais-Ribeiro (1999), state that "social support relieves distress in crisis situation, can inhibit the development of diseases and, when one is ill, has a positive role in recovery from disease". A review of studies on the epidemiological evidence of the relationship between social support and health, held by Broadhead et al. (1983), cited by Pais-Ribeiro (1999), concluded that there is a strong correlation between the 
two variables [35].

\subsection{Resilience}

Taking into account a psycho-educational perspective on health promotion and well-being, Jardim and Pereira (2006) define resilience as the ability to operate knowledge, attitudes and skills in order to prevent, minimize or overcome the damaging effects of crises and adversity. A resilient person is someone, whom, having to face an adverse situation, is able to use their intra- and inter-personal resources in such a way as to develop the skills he/she needs to be successful in personal, social and professional life [36]. Wagnild (2010) had shown that resilience protects against negative emotions and, thus, has the potential to reduce their pathophysiological effects [37]. Resilience state scale (Wagnild, 1993) integrates four factors: perseverance; meaning of life; serenity; self-reliance and existential aloneness. Perseverance refers to the enthusiastic persistence in finding solutions to problems, overcoming adversity, and the will to continue to rebuild one live, trusting on oneself with a self-regulatory attitude. Meaning of life refers to the awareness that one have something meaningful to live, to the notion that life has a meaning (a reason) in which the individual focuses, avoiding being obsessed with disputes that one can't solve, involving determination and satisfaction with the achievement of defined objectives. Serenity depends on a balanced and focused perspective on the purpose of life itself, with the ability to accept the variety of experiences (even adverse), with calm and/or enthusiasm and to exercise self-esteem. Self-reliance and existential aloneness concern the sense of oneness, the awareness that each person's life path is unique and that certain steps are not faced in a group but in solitude, getting the person to be on his/her own and being able to depend essentially on himself/herself, referring to the belief in himself/herself, in his/her abilities and interest in life, recognizing limitations and being able to depend on him/herself [38]. Martins and Jesus (2007) discuss the transactional model of resilience proposed by Kumpfer (1999). Four main areas of influence and six basic predictors of resilience are identified: the stressors (or challenges); the environmental context; the individual-environment transaction process; the internal resilience factors; the resilience process; the results of reintegration. Kumpfer (1999) argues that resilient individuals, even in involvements of high social risk, are able to deal with situations in order to find support (their families, schools, communities and peer groups) for enabling them to face appropriate opportunities for positive and healthy development. Kumpfer (1999) adds that the subject can use different strategies to adapt or modify their involvement, mainly, the use of selective perceptions, cognitive recomposition, alteration of the involvement or active coping. The transactional model of resilience demonstrates that the stressors and challenges, not counterbalanced by protective environmental and social processes or bio-psycho-spiritual resilience factors, can lead to changes or disruption in homeostasis, with individual disorganization, which can be recovered and result in the reintegration of homeostasis, if environmental and social processes of support are present: the resilient reintegration occurs when the individual has acquired a heightened state of resilience; homeostatic reintegration occurs when the individual maintains the same resilience state he/she had before the exposure to stressors or challenges; not adaptive reintegration occurs when exposure to stressors or challenges results in continued low individual state of reintegration; dysfunctional reintegration occurs when exposure to stressors or challenges results in a greater reduction in positive reintegration [39] [40].

\subsection{Monitoring of Cardiac Activity by Electrocardiography with Heart Rate Variability Function (HRV), Autonomic Influence on Heart Rate and Physiological and Pathophysiological Correlates of HRV Components}

Heart rate and cardiac rhythm depend on their control by autonomic nervous system [41]. The sympathetic and parasympathetic/vagal activities target the sinus node and are characterized by electrochemical discharges in synchrony with each cardiac cycle which may also be modulated by central oscillators (vasomotor and respiratory centers) and peripheral (blood pressure oscillation and respiratory movements) [42]. In resting conditions, vagal tone prevails [43]. The parasympathetic system influences heart rate by releasing acetylcholine, and its muscarinic receptors respond with increased conductance of cell membrane to potassium ion [44]-[46]. The efferent vagal activity is the main contributor to the high frequency component (HF) of heart rate variability (HRV) [47] [48]. The increase of HF is induced by breath's control, cold stimulation of the face and rotational stimuli [49]. The sympathetic influence on heart rate is mediated by the release of adrenaline and noradrenaline, and the activation of beta-adrenergic receptors results in phosphorylation of membrane proteins mediated by adenosine 3',5'-cyclic monophosphate (cAMP) (molecular transductor of the signal within a cell, cellular second messen- 
ger). Low frequency component of heart rate variability (LF) is considered a marker of sympathetic modulation [50] [51]. Increased LF is induced by a variety of situations: orthostatic position, stress, moderate exercise in healthy subjects, moderate hypotension and coronary artery occlusion [50]. The LF/HF ratio reflects the sympathetic-vagal balance (or sympathetic modulation) of cardiac function. Autonomic failure (dysautonomia), as high levels of sympathetic activity, determines decreased HRV. Decreased HRV is caused by various heart disorders and other than heart diseases (diabetes). In accordance with the Task Force of the European Society of Cardiology and the North American Society of Pacing Electrophysiology, normal standard values of the most important HRV parameters are, in normalized units (nu): LF power equals 54 (average), with a standard deviation of 4; HF power equals 29 (average), with a standard deviation of 3; ratio LF/HF equals 1.5 - 2.0 (average) [52].

\section{Empirical Study}

\subsection{Methods}

It has been performed a recruitment of citizens with low financial incomes, without assigned diagnoses, particularly concerning neurological and/or psychiatric disorders, which integrates a convenience sample. The participants provided previous written, free and informed, consent. This is a transversal, quantitative, correlational, not experimental, study. The questionnaires and psychometric scales used are validated for Portuguese population. It has been performed a spectral analysis, with fast Fourier transform, of heart rate, during five minutes per participant, and evaluated the components/parameters of their heart rate variability (HRV), in accordance with standard procedures, as established by the Task Force of the European Society of Cardiology and the North American Society of Pacing Electrophysiology, in order to study the impact of stress, related with/caused by economic insufficiency (poverty), on cardiovascular function/health [52].

\subsection{Participants}

The sample consists of 33 elements. $48 \%$ of the participants are female. Data have been collected between 17 and 23 October of 2013. The age has a mean value of 53.8 years, with a dispersion of values of $11 \%$. $97 \%$ of the participants live in the city of Olhão, Portugal. 24\% of the participants are single, $49 \%$ are married, 3\% are separated, $12 \%$ are divorced and $12 \%$ are widowed. On academic/literary abilities (scholarship), 40\% of the participants have the primary 4 th grade, $6 \%$ have the primary 5 th grade, $21 \%$ have the primary 6 th grade, $15 \%$ have the primary 9 th grade, $3 \%$ have the primary 11 th grade and $15 \%$ have the primary 12 th grade. $40 \%$ of the participants are unemployed, $12 \%$ are retired, $6 \%$ are pensioners (the remaining participants do not answer). The net/liquid monthly income has a mean value of 337 euros, with a dispersion of values of $69 \%$. The distribution of values of net/liquid monthly income is verified mainly between 200 and 500 euros. In the sample, the monthly expenses have a mean value of 376 euros, with a dispersion of values of $47 \%$. The distribution of values of monthly expenses is verified mainly between 200 and 600 euros. The difference between incomes and expenses has a monthly mean value of -28.20 euros, with a dispersion of values of $746 \%$. The distribution of the difference values between monthly incomes and expenses occurs mainly between -200 and -100 euros and between 0 and 100 euros. 94\% of the participants believe that their financial situation has worsened over the past two years. $97 \%$ of participants believe that their financial situation will worsen in the coming years. $24 \%$ of the participants consider that past financial difficulties were mild, 36\% moderate and 40\% severe. 27\% of the participants have not been involved in providing care and financial help to family and 73\% respond affirmatively to the same question. 52\% of participants say they do not suffer from chronic diseases. The remaining participants suffer from: cancer; diabetes; ischemic heart disease; arrhythmia; hypercholesterolemia; hypertension; myasthenia gravis.

\subsection{Material}

\subsubsection{Questionnaire on Preoccupation}

The questionnaire on preoccupation (QP) is an ordinal Likert scale with five possible answers (“ 1 ” to “5”) between "I disagree very much" and "I agree very much". It consists of 16 items, which are organized in one dimension, and, for the items marked with an "R", the scale is recoded in the reverse order, because its formulation is held in a negative form: item R1-If I do not have time to do everything, I do not worry about it; item 
2-My preoccupations dominate me; item R3 item—I tend not to worry about things; item 4—Many situations bother me; item 5-I know I should not concern myself with things, but I cannot prevent it; item 6-When I'm under pressure, I worry very much; item 7-I'm always worried; item R8-I believe it is easy to ignore troublesome thoughts; item 9-Once I've finished a task, I start worrying about everything else I have to do; item R10 item-I never worry about anything; item R11-When there's nothing I can do about a concern, I do not turn to look into it; item 12-I have always been a worried person; item 13-I notice that I have been worrying about things; item 14-When I start to worry, I can no longer stop to do so; item 15-I worry all the time; item 16 - I worry about my projects until they are completed.

\subsubsection{Questionnaire on Health Status}

The questionnaire on health status (QHS) is an ordinal Likert scale with six possible answers (from " 0 " to "5") between "never" and "always." It consists of 12 items, which are organized in one dimension and, for items marked with an "R", the scale is recoded in reverse order, because its formulation is held in a negative form: item 1 -Were you able to concentrate on what you were doing?; item R2—Have you lost sleep due to concerns?; item 3-Did you feel yourself to be useful in important things?; item 4-Were you able to make decisions about things?; item R5—Did you feel constantly under stress?; item R6—Did you feel that you were unable to overcome your difficulties?; item 7-Were you able to enjoy your daily activities?; item 8-Were you able to face your problems?; item R9—Have you been unhappy and depressed?; item R10—Have you lost self-confidence?; item R11—Have you thought on yourself as a worthless person?; item 12—Did you feel reasonably happy, all things considered?.

\subsubsection{Questionnaire on Financial Management}

The questionnaire on financial management (QFM) is an ordinal Likert scale with five possible answers (" 1 " to “5”) between "I disagree very much" and "I agree very much". It consists of 8 items, which are organized in one dimension, and, for the items marked with an "R", the scale is recoded in reverse order, because its formulation is held in a negative form: item R1-I'm uncomfortable with the amount of debt that I have; item R2-I am concerned with the payment of my loans; item R3-I am concerned with the payment of my credit cards; item 4-I think I have a good financial condition; item R5-I think a lot about the debts that I have; item R6 - I had discussions with other people (family, friends and significant others) about my spending level; item 7—Five years from now, I will not have debts with my credit cards; item 8-Within one year, I will not have debts with my credit cards.

\subsubsection{Questionnaire on Financial Situation}

The questionnaire on financial situation (QFS) is an ordinal Likert scale with five possible answers (" 1 " to " 5 ") between "nothing" and "much". It consists of 6 items, which are organized in one dimension, and, for all items marked with an "R", the scale is recoded in reverse order, because its formulation is held in a negative form: item R1-How insecure do you feel?; item R2—How at risk do you feel?; item R3-How threatened do you feel?; item R4-How much do you worry about it?; item R5-How much do you think about it?; item R6-What is the probability to declare bankruptcy/failure to manage your debt?.

\subsubsection{Questionnaire on Financial Restraints}

The questionnaire on financial restraints (QFR) is an ordinal Likert scale with four possible answers ("1" to "4”) between "never" and "often". It consists of 10 items, which are organized in one dimension: item 1-Did you cut in spending on social activities and entertainment?; item 2-Did you postpone major purchases for the home/ family?; item 3-Did you postpone the purchase of clothing?; item 4-Did you change the travel habits to save money?; item 5-Did you change the way to buy food or the eating habits to save money?; item 6-Did you decrease contributions to charity?; item 7-Did you reduce the use of utilities for home?; item 8-Did you sell some goods?; item 9—Did you postpone medical care to save money?; item 10—Did you have additional jobs to help pay the costs?.

\subsubsection{Positive and Negative Affects Scale}

Positive and negative affects scale (PANAS) is an ordinal Likert scale with five possible answers (“1" to " 5 ”) 
between "none or very little" and "extremely". It consists of 20 items, which are organized in two dimensions (one for positive affects, other for negative affects) [53] [54].

\subsubsection{1-Item Depression, Anxiety and Stress Scales}

Depression, anxiety and stress scales (DASS) constitute an ordinal Likert scale with four response alternatives (from "0"a " 3 ") between "not applied to me" and "applied to me, most of the time". The short version of DASS consists of 21 items, which are organized in three dimensions. Seven variables measure appropriately a single dimension, depression. The cutoff point for depression scale is greater than 7 , that is the elements with a higher score than 7 exhibit depression. Seven variables measure appropriately a single dimension, anxiety. The cutoff point for anxiety scale is greater than 9 , that is the elements with a higher feature score than 9 exhibit. Seven variables measure appropriately a single dimension, stress. The cutoff point for the stress range is greater than 14 , that is the elements with a higher score than 14 show stress [55] [56].

\subsubsection{Satisfaction with Social Support Scale}

Satisfaction with social support scale (SSSS) is an ordinal Likert scale with five possible answers (" 1 " to " 5 ") between "I totally agree" and "I totally disagree". It consists of 15 items, which are organized into four dimensions, and, for items marked with an " $\mathrm{R}$ ", the scale is recoded in reverse because its formulation is held in the negative. This rating scale integrates the dimensions: satisfaction with friends; intimacy; satisfaction with family; social activities) [35] [57].

\subsubsection{Revised Life Orientation Test}

Revised life orientation test (LOT-R) is an ordinal Likert scale with five possible answers (“1” to "5”) between "I totally disagree" and "I totally agree". It consists of 5 items, which are organized in one dimension, and for the items marked with an "R" range is recoded in reverse order, because its formulation is held in the negative [31] [58].

\subsubsection{Resilience State Scale}

Resilience state scale (RSS) is an ordinal Likert scale with seven possible answers (" 1 " to "7") between "I totally disagree" and "I totally agree". It consists of 23 items, which are organized in a single dimension. Their values were determined by calculating the sum of the items that constitute them. The minimum value is 23 and the maximum value is 161 [38] [59].

\subsubsection{Loneliness Scale}

Loneliness scale (LS) is an ordinal Likert scale with four response alternatives ("1" through "4") between "never" and "often". It consists of 18 items, which are organized in a single dimension and, for items marked with an " $\mathrm{R}$ ", the scale is recoded in reverse because its formulation is held in the negative [60] [61].

\section{Results}

The QP has a mean value greater than the midpoint of the measurement scale, which is 48 , and most of the values are found between 40 and 70 . The QHS also has a mean value greater than the intermediate point of the measurement scale, which is 30 , and the values are distributed between 20 and 55 . The QFM has a mean value lower than the midpoint of the measurement scale, which is 24 , and most of the values are located between 15 and 30. The same is true for QFS, with a mean value below the midpoint of the measurement scale, which is 18 , and most of the values are located between 5 and 15. The QFR has a mean value above the midpoint of the measurement scale, which is 25 , and most of the values are located between 30 and 40 . PANAS for positive affects has a mean value of 30 (precisely at the midpoint of the measurement scale), and most of the values are located between 25 and 40. PANAS for negative affects has a mean value lower than the midpoint of the measurement scale, which is 30 , and most of the values are located between 10 and 35 . DASS for depression has a mean value below the midpoint of the measurement scale, and most of the values are located between 0 and 12 . DASS for anxiety has a mean value lower than the midpoint of the measurement scale, which is 10.5 , and most of the values are located between 0 and 9 . DASS for stress has a mean value lower than the midpoint of the measurement scale, and most of the values are located between 0 and 12. LS has a mean value lower than the 
midpoint of the measurement scale, and most of the values are located between 30 and 55 . SSSS has a mean value slightly higher than the midpoint of the measurement scale, and most of the values are located between 40 and 60. LOT-R for dispositional optimism has a mean value above the midpoint of the measurement scale, and most of the values are located between 15 and 25. RSS has a mean value of 129.2, well above the midpoint of the measurement scale, which is 92, and most of the values are located between 115 and 145 . The internal consistency of the psychometric instruments used in this study are analyzed with Cronbach's alpha coefficient, and the obtained levels are good and very good (0.740 for QP; 0.805 for QHS; 0.796 for QFM; 0.904 for QFS; 0.862 for QFR; 0.703 for PANAS for positive affects; 0.890 for PANAS for negative affects; 0.836 for DASS for depression; 0.868 for DASS for anxiety; 0.896 for DASS for stress; 0.894 for SSSS; 0.816 for LOT-R for dispositional optimism; 0.695 for RSS; 0.873 for LS).Total power parameter of HRV has a mean value of 1344.6 with a dispersion of values of $202 \%$, and the distribution of their values occurs mainly between 0 and 2000 . Low frequency (LF) power parameter of HRV has a mean value of 64.95 with a dispersion of the values of $36 \%$, and the distribution of their values occurs mainly between 70 and 90 . High frequency (HF) power of HRV has a mean value of 21.88, with a distribution of values mostly between 5 and 25. Total mean heart rate (HR) value is 88.12 with a dispersion of values of $37 \%$, and the distribution of the values occurs mainly between 70 to 100 . LF/HF ratio has a mean value of 4.34 , with a distribution of values mostly between 0 and 5 . All variables whose relations are studied are quantitative and therefore can be analyzed using Pearson's correlation coefficient $r$. There are negative correlations between: RSS and DASS for depression, $r=-0.359$, $p=0.040$; QFM and LS, $r=-0.404$, $\mathrm{p}=0.022$; QFS and PANAS for negative affects, $r=-0.382, \mathrm{p}=0.028$; QFS and $\mathrm{LS}, \mathrm{r}=-0.458, \mathrm{p}=0.008$; PANAS for negative affects and SSSS, $r=-0.550, p=0.001$; PANAS for negative affects and LOT-R for dispositional optimism, $r=-0.465$, $p=0.008$; DASS for depression and SSSS, $r=-0.447, p=0.009$; DASS for depression and LOT-R for dispositional optimism, $r=-0.485, \mathrm{p}=0.006$; DASS for anxiety and SSSS, $r=-0.377$, $\mathrm{p}=0.030$; DASS for anxiety and LOT-R for dispositional optimism, $r=-0.483, p=0.006$; DASS for stress and SSSS, $r=-0.388, p=0.026$; DASS for stress and LOT-R for dispositional optimism, $r=-0.506, p=0.004$; QFM and LF/HF, $\mathrm{r}=-0.407, \mathrm{p}=0.019$.There are positive correlations between: DASS for stress and PANAS for negative affects, $r=0.785, \mathrm{p}<0.001$; DASS for depression and PANAS for negative affects, $\mathrm{r}=0.711$, $\mathrm{p}<$ 0.001; DASS for anxiety and PANAS for negative affects, $r=0.678, \mathrm{p}<0.001$; DASS for depression and LS, $\mathrm{r}=$ $0.411, \mathrm{p}=0.019$; RSS and PANAS for positive affects, $\mathrm{r}=0.494, \mathrm{p}=0.003$; QFR and PANAS for negative affects, $r=0.507, p=0.003$; QFR and LS, $r=0.480, p=0.005$; QHS and SSSS $r=0.382, p=0.028$; QHS and LOT-R for dispositional optimism, $r=0.427, p=0.016$; LS and LF/HF ratio, $r=0.399, p=0.024$; QFM and HF power, $\mathrm{r}=0.450, \mathrm{p}=0.009$.

\section{Discussion and Conclusions}

In this study, the net/liquid monthly income has a mean value of 337 euros, and net/liquid monthly expenses have a mean value of 376 euros. Financial restraints (QFR) correlate positively with negative affects (PANAS). Measures consisting generically in increasing personal financial income determine: a reduction in hospitalization for mental health problems [8]; lower consumption of anxiolytics [9]; increased mental health [10]-[12]. Poverty causes negative affects and stress [13]. The majority of the participants don't hold any employment relationship. The lack of employment results in financial difficulties, and poverty results in reduced opportunity to obtain gainful employment. Unemployed persons and those who fail to obtain employment have more depressive symptoms than individuals who can get a job [2]. None of the participants has higher educational background (40\% of the participants have the primary 4th grade, $6 \%$ have the primary 5th grade, $21 \%$ have the primary 6 th grade, $15 \%$ have the primary 9 th grade, $3 \%$ have the primary 11 th grade and $15 \%$ have the primary 12th grade). Limited resources, resulting in reduced opportunity for education which prevents access to most skilled jobs, increase individual vulnerability and insecurity, contributing to a persistently low social capital. The prevalence of common mental disorders is higher among individuals with low levels of education [1]. In this work, negative affects (PANAS) correlate positively with depression, anxiety and stress (DASS). Watson and Clark (1984) concluded that individuals who express high levels of negative affectivity envisage themselves and their involvement in generally negative terms [20]. Individuals with high negative affectivity levels have higher levels of stress, anxiety and dissatisfaction with life, and tend to focus on unpleasant aspects of themselves, the world, the future and others [21]. The tripartite model of anxiety and depression, developed by Clark and Watson (1991), proposes that anxiety and depressive disorders overlap considerably by a general, not specific, factor, 
negative affectivity, which reflects the level of aversive feelings present in an individual. The two remaining factors of this model are positive affectivity, which, when low, is relatively specific for depression, and physiological activation, which is relatively specific to anxiety [22]. Lovibond and Lovibond (1995), authors of anxiety, depression and stress scales (DASS), assume that psychological disorders are not categories, that is, the differences between depression, anxiety and stress, experienced by normal subjects and patients, are essentially level ones: depression is characterized mainly by the loss of self-esteem and motivation, and is associated with the perception of low probability of achieving life goals that are meaningful to the individual as a person; anxiety emphasizes the links between persistent state of anxiety and intense fear responses; stress suggests states of excitement and persistent tension, with low resistance to frustration and disappointment [23]. The majority of the participants haven't marital life. In this work, loneliness correlates positively with economic insufficiency. The onset of loneliness is often initiated by a previous event, usually a change or loss in/of an emotional relationship, through death or divorce, or a disruption of social relationship created by the move to a new school, city or employment. Classically, it is distinguished emotional loneliness from social loneliness, wherein the first encompasses the lack of emotional ties inherent to intimate relationships, while bereavement, divorce or emptiness feelings within marriage are the likely background of this latter kind of loneliness. Loss of employment, exclusion from the peer group and not belonging to community organizations are the likely history of social loneliness. Several studies have shown that loneliness is more prevalent among lower financial income groups [30]. Dispositional optimism (LOT-R) and social support (SSSS), factors that positively support health (QHS), protect, in negative correlation, against the negative impact of negative affects (PANAS) associated with financial restraints (QFR), on health of the population which integrates this study. Chang (1998) found that dispositional optimism is a significant moderator of the relationship between stress and psychological well-being [33]. Vickers and Vogeltanz (2000) found that the lack of optimism is a predictor of depression [34]. Rodin and Salovey (1989), cited by Pais-Ribeiro (1999), state that "social support relieves distress in crisis situation, can inhibit the development of diseases and, when one is ill, has a positive role in recovery from disease” [35]. Financial management (QFM) is negatively correlated with the lack of cardiovascular health, and cardiovascular dysfunction correlates positively with loneliness (LS), in this study. Increased low frequency parameter of heart rate variability (HRV) LF is induced by a variety of situations, including stress [50]. Positive affects (PANAS) correlate positively with resilience skills (RSS), which correlate negatively with depression (DASS). Wagnild (2010) had shown that the resilience protects against negative emotions and, thus, has the potential to reduce their pathophysiological effects [37]. Positive affectivity provides a rupture of stress and supports ongoing efforts to replenish depleted resources from stress [19]. In summary, psychobiological therapeutic interventions and psychotherapy, which also target psychological dysfunction related with economic behavior of persons in a situation of poverty, would be beneficial.

\section{References}

[1] Patel, V. and Kleinman, A. (2003) Poverty and Common Mental Disorders in Developing Countries. Bulletin of the World Health Organization, 81, 609-615.

[2] Simon, G.E., Revicki, D., Heiligenstein, J., Grothaus, L., VonKorff, M., Katon, W.J. and Hylan, T.R. (2000) Recovery from Depression, Work Productivity, and Health Care Costs among Primary Care Patients. General Hospital Psychiatry, 22, 153-162. http://dx.doi.org/10.1016/S0163-8343(00)00072-4

[3] Lund, C., Breen, A., Flisher, A.J., Kakuma, R., Corrigall, J., Joska, J.A., Swartz, L. and Patel, V. (2010) Poverty and Common Mental Disorders in Low and Middle Income Countries: A Systematic Review. Social Science \& Medicine, 71, 517-528. http://dx.doi.org/10.1016/j.socscimed.2010.04.027

[4] Cohen, S., Schwartz, J.E., Epel, E., Kirschbaum, C., Sidney, S. and Seeman, T. (2006) Socioeconomic Status, Race, and Diurnal Cortisol Decline in the Coronary Artery Risk Development in Young Adults (CARDIA) Study. Psychosomatic Medicine, 68, 41-50. http://dx.doi.org/10.1097/01.psy.0000195967.51768.ea

[5] Cohen, S., Doyle, W.J. and Baum, A. (2006) Socioeconomic Status Is Associated with Stress Hormones. Psychosomatic Medicine, 68, 414-420. http://dx.doi.org/10.1097/01.psy.0000221236.37158.b9

[6] Li, L., Power, C., Kelly, S., Kirschbaum, C. and Hertzman, C. (2007) Life-Time Socio-Economic Position and Cortisol Patterns in Mid-Life. Psychoneuroendocrinology, 32, 824-833. http://dx.doi.org/10.1016/j.psyneuen.2007.05.014

[7] Saridjan, N.S., Huizink, A.C., Koetsier, J.A., Jaddoe, V.W., Mackenbach, J.P., Hofman, A., Kirschbaum, C., Verhulst, F.C. and Tiemeier, H. (2010) Do Social Disadvantage and Early Family Adversity Affect the Diurnal Cortisol Rhythm 
in Infants? The Generation R Study. Hormones and Behavior, 57, 247-254.

http://dx.doi.org/10.1016/j.yhbeh.2009.12.001

[8] Costello, E.J., Compton, S.N., Keeler, G. and Angold, A. (2003) Relationships between Poverty and Psychopathology: A Natural Experiment. JAMA, 290, 2023-2029. http://dx.doi.org/10.1001/jama.290.15.2023

[9] Cesarini, D., Lindqvist, E., Östling, R. and Wallace, B. (2013) Estimating the Causal Impact of Wealth on Health: Evidence from the Swedish Lottery Players. New York University Working Paper, New York. http://webmeets.com/files/papers/res/2014/1050/Health\%20RES.pdf

[10] Case, A. (2004) Does Money Protect Health Status? Evidence from South African Pensions. In: Wise, D.A., Ed., Perspectives on the Economics of Aging, University of Chicago Press, Chicago, 287-312. http://www.nber.org/chapters/c10346.pdf http://dx.doi.org/10.7208/chicago/9780226903286.003.0008

[11] Gardner, J. and Oswald, A.J. (2007) Money and Mental Wellbeing: A Longitudinal Study of Medium-Sized Lottery Wins. Journal of Health Economics, 26, 49-60. http://dx.doi.org/10.1016/j.jhealeco.2006.08.004

[12] Apouey, B. and Clark, A.E. (2014) Winning Big but Feeling No Better? The Effect of Lottery Prizes on Physical and Mental Health. Health Economics, 24, 516-538. http://dx.doi.org/10.1002/hec.3035

[13] Schwabe, L. and Wolf, O.T. (2009) Stress Prompts Habit Behavior in Humans. Journal of Neuroscience, 29, 71917198. http://dx.doi.org/10.1523/JNEUROSCI.0979-09.2009

[14] Spears, D. (2011) Economic Decision-Making in Poverty Depletes Behavioral Control. The BE Journal of Economic Analysis \& Policy, 11, 1935-1682. http://dx.doi.org/10.2202/1935-1682.2973

[15] Muraven, M. and Baumeister, R.F. (2000) Self-Regulation and Depletion of Limited Resources: Does Self-Control Resemble a Muscle? Psychological Bulletin, 126, 247-259. http://dx.doi.org/10.1037/0033-2909.126.2.247

[16] Haushofer, J. and Fehr, E. (2014) On the Psychology of Poverty. Science, 344, 862-867. http://dx.doi.org/10.1126/science.1232491

[17] Seligman, M.E., Steen, T.A., Park, N. and Peterson, C. (2005) Positive Psychology Progress: Empirical Validation of Interventions. American Psychologist, 60, 410-421. http://dx.doi.org/10.1037/0003-066X.60.5.410

[18] Naragon, K. and Watson, D. (2009) Positive Affectivity. In: Lopez, S., Ed., The Encyclopedia of Positive Psychology, Wiley-Blackwell, Hoboken, 707-711.

[19] Southwick, S.M., Vythilingarn, M. and Charney, D.S. (2005) The Psychobiology of Depression and Resilience to Stress: Implications for Prevention and Treatment. Annual Review of Clinical Psychology, 1, 255-291. http://dx.doi.org/10.1146/annurev.clinpsy.1.102803.143948

[20] Watson, D. and Clark, L.A. (1984) Negative Affectivity: The Disposition to Experience Negative Aversive Emotional States. Psychological Bulletin, 96, 465-490. http://dx.doi.org/10.1037/0033-2909.96.3.465

[21] Watson, D., Clark, L.A. and Carey, G. (1988) Positive and Negative Affectivity and Their Relation to Anxiety and Depressive Disorders. Journal of Abnormal Psychology, 97, 346-353. http://dx.doi.org/10.1037/0021-843X.97.3.346

[22] Clark, L.A. and Watson, D. (1991) Tripartite Model of Anxiety and Depression: Psychometric Evidence and Taxonomic Implications. Journal of Abnormal Psychology, 100, 316-336. http://dx.doi.org/10.1037/0021-843X.100.3.316

[23] Lovibond P.F. and Lovibond, S.H. (1995) The Structure of Negative Emotional States: Comparison of the Depression Anxiety Stress Scales (DASS) with the Beck Depression and Anxiety Inventories. Behaviour Research and Therapy, 33, 335-342. http://dx.doi.org/10.1016/0005-7967(94)00075-U

[24] Jacobs, G.D. and Snyder, D. (1996) Frontal Brain Asymmetry Predicts Affective Style in Men. Behavioral Neuroscience, 110, 3-6. http://dx.doi.org/10.1037/0735-7044.110.1.3

[25] Tomarken, A.J. and Davidson, R.J. (1994) Frontal Brain Activation in Repressors and Nonrepressors. Journal of Abnormal Psychology, 103, 339-349. http://dx.doi.org/10.1037/0021-843X.103.2.339

[26] Allen, J.J., Iacono, W.G., Depue, R.A. and Arbisi, P. (1993) Regional Electroencephalographic Asymmetries in Bipolar Seasonal Affective Disorder before and after Exposure to Bright Light. Biological Psychiatry, 33, 642-646. http://dx.doi.org/10.1016/0006-3223(93)90104-L

[27] Henriques, J.B. and Davidson, R.J. (1990) Regional Brain Electrical Asymmetries Discriminate between Previously Depressed and Healthy Control Subjects. Journal of Abnormal Psychology, 41, 22-31. http://dx.doi.org/10.1037/0021-843X.99.1.22

[28] Henriques, J.B. and Davison, R.J. (1991) Left Frontal Hypoactivation in Depression. Journal of Abnormal Psychology, 100, 535-545. http://dx.doi.org/10.1037/0021-843X.100.4.535

[29] George, M.S. and Post, R.M. (2011) Daily Left Prefrontal Repetitive Transcranial Magnetic Stimulation for Acute Treatment of Medication-Resistant Depression. Perspectives, 168, 356-364. 
http://dx.doi.org/10.1176/appi.ajp.2010.10060864

[30] Perlman, D. and Peplau, L. (1998) Loneliness. In: Friedman, H.S., Ed., Encyclopedia of Mental Health, Vol. 2, Academic Press, San Diego, 571-581.

[31] Scheier, M.F., Carver, C.S. and Bridges, M.W. (1994) Distinguishing Optimism from Neuroticism (and Trait Anxiety, Self-Mastery, and Self-Esteem): A Re-Evaluation of the Life Orientation Test. Journal of Personality and Social Psychology, 67, 1063-1078. http://dx.doi.org/10.1037/0022-3514.67.6.1063

[32] Segerstrom, S. and Nes, L. (2006) When Goals Conflict but People Prosper: The Case of Dispositional Optimism. Journal of Research in Personality, 40, 675-693. http://dx.doi.org/10.1016/j.jrp.2005.08.001

[33] Chang, E. (1998) Does Dispositional Optimism Moderate the Relation between Perceived Stress and Psychological Well-Being? A Preliminary Investigation. Personality and Individual Differences, 25, 233-240. http://dx.doi.org/10.1016/S0191-8869(98)00028-2

[34] Vickers, K. and Vogeltanz, N. (2000) Dispositional Optimism as a Predictor of Depressive Symptoms over Time. Personalityand Individual Differences, 28, 259-272. http://dx.doi.org/10.1016/S0191-8869(99)00095-1

[35] Pais-Ribeiro, J. (1999) Escala de Satisfação com o Suporte Social (ESSS). Análise Psicológica, 3, 547-558. http://hdl.handle.net/10216/5544

[36] Jardim, J. and Pereira, A. (2006) Competências pessoais e sociais: Guia prático para a mudança positiva. Edições ASA, Porto.

[37] Wagnild, G.M. (2010) Discovering Your Resilience Core. http://resiliencescale.net/papers.html

[38] Wagnild, G.M. and Young, H.M. (1993) Development and Psychometric Evaluation of the Resilience Scale. Journal of Nursing Measurement, 1, 165-178.

[39] Martins, M. and Jesus, S. (2007) Factores de resiliência e bem-estar: Compreender e actuar para resistir. In: Siqueira, M.M.M., Jesus, S.N. and Oliveira, V.B., Orgs., Psicologia da Saúde, Teoria e Pesquisa, Universidade Metodista de São Paulo \& Universidade do Algarve, São Bernardo do Campo, 85-113.

[40] Kumpfer, K.L. (1999) Factors and Processes Contributing to Resilience: The Resilience Framework. In: Glantz, M.D. and Johnson, J.L., Eds., Resilience and Development: Positive Life Adaptations, Kluwer, New York, 179-224.

[41] Jalife, J. and Michaels, D.C. (1994) Neural Control of Sinoatrial Pacemaker Activity. In: Levy, M.N. and Schwartz, P.J., Eds., Vagal Control of the Heart: Experimental Basis and Clinical Implications, Futura, Armonk, 173-205.

[42] Malliani, A., Pagani, M., Lombardi, F. and Cerutti, S. (1991) Cardiovascular Neural Regulation Explored in the Frequency Domain. Circulation, 84, 1482-1492. http://dx.doi.org/10.1161/01.CIR.84.2.482

[43] Levy, M.N. (1971) Sympathetic-Parasympathetic Interactions in the Heart. Circulation Research, 29, 437-445. http://dx.doi.org/10.1161/01.RES.29.5.437

[44] Noma, A. and Trautwein, W. (1978) Relaxation of the ACh-Induced Potassium Current in the Rabbit Sinoatrial Node Cell. Pflügers Archiv, 377, 193-200. http://dx.doi.org/10.1007/BF00584272

[45] Osterrieder, W., Noma, A. and Trautwein, W. (1980) On the Kinetics of the Potassium Channel Activated by Acetylcholine in the S-A Node of the Rabbit Heart. Pflügers Archiv, 386, 101-109. http://dx.doi.org/10.1007/BF00584196

[46] Sakmann, B., Noma, A. and Trautwein, W. (1983) Acetylcholine Activation of Single Muscarinic K ${ }^{+}$Channels in Isolated Pacemaker Cells of the Mammalian Heart. Nature, 303, 250-253. http://dx.doi.org/10.1038/303250a0

[47] Akselrod, S., Gordon, D., Ubel, F.A., Shannon, D.C., Berger, A.C. and Cohen, R.J. (1981) Power Spectrum Analysis of Heart Rate Fluctuation: A Quantitative Probe of Beat to Beat Cardiovascular Control. Science, 213, 220-222. http://dx.doi.org/10.1126/science.6166045

[48] Pomeranz, B., Macaulay, R.J.B., Caudill, M.A., Kutz, I., Adam, D., Gordon, D., et al. (1985) Assessment of Autonomic Function in Humans by Heart Rate Spectral Analysis. American Journal of Physiology-Heart and Circulatory Physiology, 248, H151-H153. http://ajpheart.physiology.org/content/ajpheart/248/1/H151.full.pdf

[49] Kamath, M.V. and Fallen, E.L. (1992) Power Spectral Analysis of Heart Rate Variability: A Noninvasive Signature of Cardiac Autonomic Function. Critical Reviews in Biomedical Engineering, 21, 245-311.

[50] Rimoldi, O., Pierini, S., Ferrari, A., Cerutti, S., Pagani, M., Malliani, A. (1990) Analysis of Short-Term Oscillations of R-R and Arterial Pressure in Conscious Dogs. American Journal of Physiology-Heart and Circulatory Physiology, 258, H967-H976.

[51] Montano, N., Ruscone, T.G., Porta, A., Lombardi, F., Pagani, M. and Malliani, A. (1994) Power Spectrum Analysis of Heart Rate Variability to Assess the Changes in Sympathovagal Balance during Graded Orthostatic Tilt. Circulation, 90, 1826-1831. http://dx.doi.org/10.1161/01.CIR.90.4.1826

[52] Malik, M., Bigger, J.T., Camm, A.J., Kleiger, R.E., Malliani, A., Moss, A.J. and Schwartz, P.J. (1996) Heart Rate Va- 
riability Standards of Measurement, Physiological Interpretation, and Clinical Use. European Heart Journal, 17, 354381. http://dx.doi.org/10.1093/oxfordjournals.eurheartj.a014868

[53] Watson, D., Clark, L.A. and Tellegen, A. (1988) Development and Validation of Brief Measures of Positive Affect and Negative Affect: The PANAS Scales. Journal of Personality and Social Psychology, 54, 1063-1070. http://dx.doi.org/10.1037/0022-3514.54.6.1063

[54] Galinha, I.C. and Pais-Ribeiro, J.L. (2005) Contribuição para o estudo da versão portuguesa da Positive and Negative Affect Schedule (PANAS): I—Abordagem teórica ao conceito de afecto. Análise Psicológica, 2, 209-218. http://www.scielo.oces.mctes.pt/pdf/aps/v23n2/v23n2a11.pdf

[55] Lovibond, S.H. and Lovibond, P.F. (1995) Manual for the Depression Anxiety Stress Scales. 2nd Edition, Psychology Foundation of Australia, Sidney.

[56] Pais-Ribeiro, J., Honrado, A. and Leal, I. (2004) Contribuição para o estudo da Adaptação Portuguesa das Escalas de Ansiedade, Depressão e Stress (EADS) de 21 itens de Lovibond e Lovibond. Psicologia, Saúde \& Doenças, 5, 229-239. http://hdl.handle.net/10400.12/1058

[57] Sarason, I.G., Levine, H.M., Basham, R.B. and Sarason, B.R. (1983) Assessing Social Support: The Social Support Questionnaire. Journal of Personality and Social Psychology, 44, 127-139. http://dx.doi.org/10.1037/0022-3514.44.1.127

[58] Pais-Ribeiro, J., Pedro, L. and Marques, S. (2012) Dispositional Optimism Is Unidimensional or Bidimensional? The Portuguese Revised Life Orientation Test. The Spanish Journal of Psychology, 15, 1259-1271. http://dx.doi.org/10.5209/rev_SJOP.2012.v15.n3.39412

[59] de Carvalho Ng, C.A.F. and Pereira, I.D. (2012) Adaptação da "The Resilience Scale" para a população adulta portuguesa. Psicologia USP, 23, 417-433. http://www.revistas.usp.br/psicousp/article/viewFile/42178/45851 http://dx.doi.org/10.1590/S0103-65642012005000008

[60] Russell, D., Peplau, L.A. and Ferguson, M.L. (1978) Developing a Measure of Loneliness. Journal of Personality Assessment, 42, 290-294. http://dx.doi.org/10.1207/s15327752jpa4203 11

[61] Neto, F. (1989) Avaliação da solidão. Psicologia Clínica, 2, 65-79. 